\title{
Sülfodiazin, Sülfomerazin ve Sülfometazinin İyonlaşma Sabitlerinin Potansiyometrik Titrasyon Yöntemi ile Tayini
}

\author{
Dilara BAŞAT DERELII ${ }^{1 *}$, Abbase Güleren ALSANCAK ${ }^{2}$ \\ ${ }^{1}$ Bitlis Eren Üniversitesi, Tatvan Meslek Yüksekokulu, Kimya ve Kimyasal Işsleme Teknolojileri Bölümü, Bitlis \\ ${ }^{2}$ Süleyman Demirel Üniversitesi, Fen Edebiyat Fakültesi, Kimya Bölümü, Isparta \\ (ORCID: 0000-0003-1328-077X) (ORCID: 0000-0001-5889-1537)
}

\begin{abstract}
Öz
$\mathrm{Bu}$ çalıșmada sülfonamit grubu ilaçlardan sülfodiazin, sülfomerazin ve sülfometazinin biyolojik sıvılardaki çözünürlük, lipofilisite, asitlik, transfer davranışı, reseptörlere bağlanma ve geçirgenlik gibi özellikleri hakkında kritik bilgiler elde etmemizi sağlayan iyonlaşma sabiti değerleri potansiyometrik titrasyon yöntemiyle tayin edilmiştir. Bileşiklerin suda çözünürlükleri az olması sebebiyle belirli yüzdelerde metanol-su (v/v) ikili karışımlarında $25^{\circ} \mathrm{C}$ 'de çalışılmış ve verilerin değerlendirilmesinde PKPOT programı ile Gran metodu kullanılmıştır. Metanol-su ortamında hesaplanan iyonlaşma sabiti değerlerinden sudaki iyonlaşma sabiti değerlerine geçişte Yasuda- Shedlovsky ekstrapolasyon yöntemi kullanılmıştır. Sülfodiazin için iyonlaşma sabiti değerleri 2,915-6,936; sülfomerazin için 2,734-6,955; sülfometazin için ise 2,466-7,537 olarak bulunmuştur. İyonlaşma sabitlerinin potansiyometrik titrasyon yöntemiyle tayininden elde edilen veriler bu ilaç aktif bileşiklerle çalışan araştırmacılara bilgi kaynağı oluşturacaktır.
\end{abstract}

Anahtar kelimeler: Sülfonamit, iyonlaşma sabiti, potansiyometrik titrasyon.

\section{Determination of Ionization Constants of Sulfodiazine, Sulfomerazine and Sulfomethazine by Potentiometric Titration Method}

\begin{abstract}
In this study, ionization constant values were determined by potentiometric titration method which provides critical information about the properties of sulfodiazine, sulfomerazine and sulfometazine from sulfonamide group drugs such as solubility, lipophilicity, acidity, transfer behavior, binding to receptors and permeability in biological fluids. Because of the low water solubility of the compounds, $40 \%, 50 \%$ and $60 \%$ (v/v) methanol-water binary mixtures were studied at $25^{\circ} \mathrm{C}$. Gran method and PKPOT program were used to evaluate the data obtained from these 3 different media. Yasuda-Shedlovsky extrapolation method was used in the transition from ionization constant values calculated in methanol-water media to ionization constant values in water. The ionization constant values for sulfadiazine are 2,915-6,936; 2,734-6,955 for sulfomerazine; and for sulphometazine 2,466-7,537. The data obtained from determination of ionization constants by potentiometric titration method will provide information source for researchers working with this drug active compounds.
\end{abstract}

Keywords: Sulfonamide, ionization constant, potentiometric titration.

\section{Giriş}

Antibiyotiklerin en eski grubu olarak bilinen sülfonamitler, bakteriyel enfeksiyonlarda sistemik kullanılabilen ilk kemoterapötik ilaçlardır. İlk kez 1936 yılında prontosilin aktif metaboliti olarak sentez edilmiştir. Sülfonamitlerin kimyasal formülleri PABA (p-Aminobenzoik asit)'daki karboksil kökü yerine sülfonil kökü olması sebebiyle PABA'ya çok benzer (Şekil 1). Bu yapısal benzerlik sebebiyle PABA'nın yerine tepkimeye girerek folik asit sentezini başlangıç aşamasında bozar ve üremeyi

"Sorumlu yazar: dilarabasat@ hotmail.com

Geliş Tarihi: 24.12.2019, Kabul Tarihi: 09.04.2020 
durdurarak bakteriyostatik etki gösterirler [1-3]. Sülfonamitler, geniş spektrumlu ilaçlar olduğu için gram (+) ve gram (-) mikroorganizmalara karşı yüksek aktivite göstererek uzun süre kullanılmışlardır.

Penisilin ve diğer antimikrobiyal ilaçların kullanıma sunulması ile birlikte pek çok mikroorganizmada sülfonamitlere karşı direnç gelişmiş ve kullanım alanları daralmıştır. Trimetoprim ve sülfametoksazolün 1970'li yıllarda kombine edilerek spesifik enfeksiyonların tedavisinde yeniden kullanım alanı bulmuşlardır [3,4,5]. Sülfonamitler günümüzde veteriner hekimlikte bakteriyel ve protozoal hastalıkların önlenmesinde yaygın bir şekilde kullanıldığı için bu ilaçların yan etkileri ve ilaç etkileşimleri incelenmeye devam edilmektedir.<smiles>Nc1ccc(S(=O)(=O)NP)cc1</smiles>

Sulfonamides $(\mathrm{R}=\mathrm{H}$, sulfanilamide)<smiles>Nc1ccc(C(=O)O)cc1</smiles>

p-Aminobenzoic acid

Şekil 1. Sülfonamit ve PABA’nın kimyasal yapısı

İyonlaşma sabitleri $\left(\mathrm{pK}_{\mathrm{a}}\right)$; ilaç aktif maddelerinin asidik ve bazik özelliğini belirleyen temel fizikokimyasal parametredir. Herhangi bir bileşikle çalışmaya başlamadan önce $\mathrm{pK}_{\mathrm{a}}$ değerinin bilinmesi deneysel yolun belirlenmesi için gereklidir. Bir bileşiğin $\mathrm{pK}_{\mathrm{a}}$ değerinin belirlenmesi için, spektrofotometri [6-8,17], potansiyometri $[9,10,17]$, iletkenlik [11, 12], proton manyetik rezonans spektrometresi [13], çözünürlük [14], kromatografik [6,15,16,17], voltametrik [18], kalorimetrik [19], elektroforetik [20], florometrik [21], polarimetrik [22], kinetik [23], gibi çeşitli deneysel yöntemlerin yanısıra bilgisayar destekli programlar da mevcuttur [24]. Potansiyometrik titrasyon yöntemi suda çözünürlüğü az olan bileşiklerin su-organik çözücü karışımlarında yapılan iyonlaşma sabiti tayinlerinde cihazın basit ve ulaşılabilir bir düzeneğe sahip olması ve verilerin kolayca yorumlanabilmesi nedeniyle tercih edilir.

Gran metodu olarak da bilinen Gran eşitliği, güçlü bir asit kuvvetli baz titrasyonunda veya bir potansiyometrik titrasyonda denklik hacmini veya son noktasını tahmin ederek bir titrant veya titrantı standart hale getirmenin yaygın bir yoludur. Bu metotla elde edilen grafikler, cam elektrotları kalibre etmek, sulu çözeltilerin karbonat içeriğini tahmin etmek ve zayıf asitlerin ve bazların iyonlaşma sabiti değerlerini titrasyon verilerinden tahmin etmek için de kullanılmıştır [25-27].

Yasuda-Shedlovsky ekstrapolasyon yöntemi organik çözücü-su ortamında çözünebilen bileşiklerin bu ortamlardaki bir dizi çözeltisinden extrapolasyon yöntemiyle sudaki iyonlaşma sabiti değerlerine geçişi sağlayan bir yöntemdir [28, 29]. Bu sebeple suda çözünmeyen bileşiklerin sudaki iyonlaşma sabiti değerlerinin belirlenmesinde tercih edilen bir yöntemdir.

Bu çalışmada sülfomerazin, sülfodiazin ve sülfometazinin iyonlaşma sabitleri su-metanol ikili karışımlarında potansiyometrik titrasyon yöntemiyle tayin edilmiştir. Potansiyometrik veriler, su organik çözücü ikili karışımlarındaki iyonik dengeleri en küçük kareler yöntemi ile inceleyen PKPOT programı [30] ve Gran metodu kullanılarak hesaplanmıştır. \%40, \%50 ve \%60 (v/v) ortamındaki PKPOT verileri kullanılarak Yasuda Shedlosky eşitliği ile bileşiklerin sudaki $\mathrm{pK}_{\mathrm{a}}$ değerleri bulunmuştur.

\section{Materyal ve Metot}

\subsection{Kullanılan Kimyasallar ve Cihazlar}

Potansiyometrik titrasyon yöntemiyle $\mathrm{pK}_{\mathrm{a}}$ tayini yapılan bileşikler sülfadiazin, sülfamerazin, sülfometazin, Merck (Darmstadt, Germany) firması tarafindan temin edilmiştir. Baz çözeltisinin ayarlanması ve hücre kalibrasyonu için kullanılan $\mathrm{HCI}$, titrant olarak kullanılan $\mathrm{KOH}$, iyonik şiddet ayarlayıcı olarak kullanılan KCI, su ile ikili karışımları halinde çalışılan metanol Merck (Darmstadt, Germany) firmasından temin edilmiş̧ir.

Potansiyometrik titrasyonlarda pH/iyon analiz cihazı (Metleer Toledo MA 235) kullanılmış ve kombine cam elektrottan (Metler Toledo InLab $413 \mathrm{Ag} / \mathrm{AgCl}$ ) yararlanılmıştır. $\mathrm{pH}$ ölçümleri $25^{\circ} \mathrm{C} \pm$ $0,1^{\circ} \mathrm{C}$ sabit sıcaklıkta ve su banyosu (BM 402) kullanılarak $\mathrm{N}_{2}$ atmosferinde yapılmıştır. 


\section{2. Çözeltilerin Hazırlanması}

$100 \mathrm{~mL}$ 'lik \%40, \%50, \%60 (v/v) metanol-su ikili karışımları hazırlanarak bu karışımlara 0,1 M derişim elde edilecek miktarda $\mathrm{KCl}$ eklenerek, manyetik çalkalayıcı yardımıyla katının çözünmesi sağlanmıştır. Hücre kalibrasyonu için, $20 \mathrm{~mL}$ metanol-su ikili karışımından alınarak katı $\mathrm{KCl}(0,1 \mathrm{M})$ ilave edilmiştir. Asit çözeltisi için $1 \mathrm{M}$ standart $\mathrm{HCl}$ (Titrisol) çözeltisi, 0,1 M'a seyreltilerek ortamın metanol yüzdesine uygun hale getirilmiştir. Baz çözeltisi için $1 \mathrm{M}$ standart $\mathrm{KOH}$ (Titrisol) çözeltisi, 0,030 M'a seyreltilerek çalışılan metanol-su ikili karışımında titrant olarak kullanılmıştır. Çalışılan sülfodiazin, sülfomerazin ve sülfometazinin $2.0 \times 10^{-3} \mathrm{M}$ derişimindeki çözeltileri metanol-su karışımında hazırlanmış ve $15 \mathrm{~mL}$ bu çözeltiden alınarak titre edilmiştir.

\subsection{Metot}

Potansiyometrik yöntemle çalışlan bileşiklerin iyonlaşma sabitlerinin belirlenmesinde, $\% 40, \% 50$ ve \%60'lık metanol-su (v/v) derişimleri kullanılmıştır. Ortamların iyonik şiddetleri 0,1 M KCl kullanılarak ayarlanmıştır. $\mathrm{E}^{\mathrm{o}}$ standart potansiyeli hücre kalibrasyonu yapılarak belirlenmiş ve kullanılan çözücü karışımındaki $\mathrm{mV}$ değerlerinden $\mathrm{pH}$ değerlerinin elde edilmesinde Gran eşitliği kullanılmıştır. Bunun için $0,1 \mathrm{M} 20 \mathrm{~mL} \mathrm{KCl}$ içeren metanol-su ikili karışımı 0,1 M'lık 0,1'er $\mathrm{mL} \mathrm{HCl}$ çözeltisi ile toplamda 2 mL oluncaya kadar titre edilmiştir. Titrant olarak kullanılacak KOH çözeltisi derişimi, $20 \mathrm{~mL} \mathrm{0,003} \mathrm{M}$ asit çözeltisi ile titre edilerek ve Gran metodu kullanılarak yaklaşık 0,03 M olarak hesaplanmıştır. Gran eşitliği monoprotik zayıf asitler için eşitlik (1)'de gösterildiği gibi lineer bir fonksiyondur [25, 26].

$\left[\mathrm{H}^{+}\right] \mathrm{V}_{\mathrm{b}}=\mathrm{K}_{\mathrm{a}} \cdot \mathrm{V}_{\mathrm{eq}}-\mathrm{K}_{\mathrm{a}} \cdot \mathrm{V}_{\mathrm{b}}$

Burada; $\mathrm{V}_{\mathrm{b}}$ ile bazın hacmi, $\mathrm{K}_{\mathrm{a}}$ ile asitlik sabiti, $\mathrm{V}_{\text {eq }}$ ile eşdeğerlik noktasındaki hacim ifade edilmektedir. $\mathrm{V}_{\mathrm{b}}$, Eşitlik (1)'de değişkendir ve katsayısı ise eğimdir. Eğimden $K_{\mathrm{a}}$ değeri hesaplanır. $\mathrm{y}=0$ iken $\mathrm{V}_{\mathrm{eq}}=$ $\mathrm{V}_{\mathrm{b}}$ dir [27]. Bu fonksiyon $\mathrm{x}$ ekseninde $\Phi_{\mathrm{ab}}$ kullanılarak da Eşitlik (2) deki gibi formüle edilebilir.

$\left[\mathrm{H}^{+}\right] \phi_{\mathrm{ab}}=\mathrm{K}_{\mathrm{a}}-\mathrm{K}_{\mathrm{a}} \phi_{\mathrm{ab}}$

Burada; $\phi_{\mathrm{ab}}$ mol oranı olarak nötralize edilen asitin kesrini gösterir. $\phi_{\mathrm{ab}}, \mathrm{V}_{\mathrm{b}}$ ile değişmekte ve eşdeğerlik noktasındaki değeri 1'dir. Titrasyonun başlangıcında $\phi_{a b}=0$ olup Eşitlik (2)'den $K_{a}$ değeri hesaplanır [27].

Suda çözünmeyen bileşiklerin sudaki $\mathrm{pK}_{\mathrm{a}}$ değerinin hesaplanmasında Yasuda-Shedlovsky ekstrapolasyon yöntemi kullanılmıştır [28, 29]. Bunun için kullanılan eşitlik (3) aşağıda verilmiştir:

${ }_{s}^{s} p K_{a}+\log \left[H_{2} O\right]=a_{\varepsilon} \varepsilon^{-1}+b_{\varepsilon}$

${ }_{s}^{s} p K_{a}$ : Bulunan ortamdaki $\mathrm{pK}_{\mathrm{a}}$ değeri

$\varepsilon$ : Su-organik çözücü ikili karışımındaki organik çözücünün dielektrik sabiti

$a \varepsilon$ : Doğrusal eşitlikten elde edilmiş eğim değeri

$b \varepsilon$ : Doğrusal eşitlikten elde edilmiş kesim değeri

$15 \mathrm{~mL}$ 2,0x $10^{-3} \mathrm{M}$ derişimindeki sülfonamitlerin çözeltileri alınarak ayarlı $\mathrm{KOH}$ çözeltisi ile titre edilmiştir. $1 \mathrm{M} \mathrm{HCl}$ ile protonlama işlemi yapılmıştır. Titrasyonlar, her bir bileşik için üç farklı ortamda $\mathrm{N}_{2}$ atmosferinde $25^{\circ} \mathrm{C}$ 'de $3 \mathrm{kez}$ yapılmıştır. $\mathrm{pK}_{\mathrm{a}}$ hesaplamalarında Gran metodu ve PKPOT programı kullanılmıştır.

\section{Bulgular ve Tartışma}

Sülfonamitlerde ana grubu, p-aminobenzensülfonilamit yapısı oluşturur. Sülfonamit türevleri amido grubu azotu $\left(\mathrm{N}^{1}\right)$ ve aromatik amino grubu azotu $\left(\mathrm{N}^{4}\right)$ üzerinden sübstitüsyonlarla hazırlanır. Genellikle ilaç olarak kullanılan türevleri $\mathrm{N}^{1}$-sübstitüe türevleridir $[5,31]$ (Şekil 1).

Sülfonamitler, amfoterik bileşiklerdir ve iki aşamalı iyonlaşırlar (Şekil 2). $\mathrm{K}_{\mathrm{a}}$ ile aromatik aminin $\left(\mathrm{H}_{3} \mathrm{~N}(+)-\mathrm{C}_{6} \mathrm{H}_{4}-\mathrm{SO}_{2}-\mathrm{NH}-\mathrm{R}\right)$ iyonlaşmas1, $\mathrm{K}_{\mathrm{a} 2}$ ile sülfonik $\left(\mathrm{H}_{2} \mathrm{~N}_{-} \mathrm{C}_{6} \mathrm{H}_{4}-\mathrm{SO}_{2}-\mathrm{NH}-\mathrm{R}\right)$ asit grubunun 
iyonlaşması görülmektedir [32,33]. Literatür araştırması yapıldığında sülfonamit grubu bileşiklerin $\mathrm{pK}_{\mathrm{a} 1}$ değerleri 2-3 ve $\mathrm{pK}_{\mathrm{a} 2}$ değerleri ise 5-8 arasında olduğu görülmektedir (Tablo 2). Bileşik pH 3'ten küçük olduğunda, protonlanmış yani katyonik formda; bileşik pH 3-5 aralığında nötr formda, $\mathrm{pH}$ 5'ten büyük olduğunda ise anyonik formdadır. Bu nötral, katyonik veya anyonik yapıların farklılığı çözünürlük, absorbsiyon gibi özelliklerinin de değişmesine sebep olur.

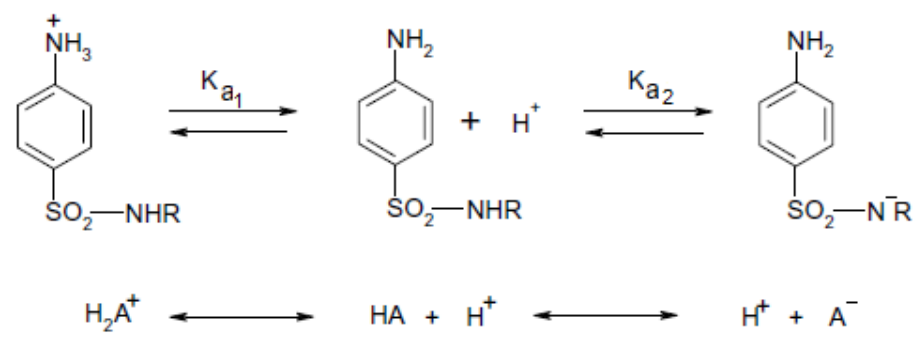

Şekil 2. Sülfonamitlerin iki aşamalı iyonlaşması

Bu çalışmada $\mathrm{pK}_{\mathrm{a}}$ sabitleri incelenen sülfodiazin, sülfomerazin ve sülfometazin bileşikleri, $\% 40$, $\% 50, \% 60(\mathrm{v} / \mathrm{v})$ metanol-su karışımlarında $2,0 \times 10^{-3} \mathrm{M}$ derişiminde hazırlanmış ve $25^{\circ} \mathrm{C}$ de titre edilmiştir. Metanol, $\mathrm{pK}_{\mathrm{a}}$ üzerindeki etkisi kapsamlı bir şekilde araştırılmış ve su-organik çözücü ikili karışımlarında yaygın bir şekilde tercih edilen bir çözücü olduğu için tercih edilmiştir [34, 35]. Ortamın iyonik şiddeti, $\mathrm{KCl}(0,1 \mathrm{M})$ ile ayarlanmıştır. Bileşikler stokiyometrik şekilde ayarlı $\mathrm{HCl}$ çözeltisi ile protonlanmış ve $\mathrm{KOH}$ ile titrasyonu yapılmıştır. Bileşikler için 2 protonun da titre edildiğini gösteren çift dönüm noktalı titrasyon eğrileri elde edilmiştir (Şekil 3,4,5). Her bir ortamda Gran metodu ve PKPOT ile elde edilen $\mathrm{pK}_{\mathrm{a}}$ değerleri Tablo 1' de verilmiştir. Bu ortamlarda elde edilen PKPOT verileri Yasuda Shedlosky ekstrapolasyon yöntemiyle değerlendirilmiş ve sudaki $\mathrm{pK}_{\mathrm{a}}$ değerleri elde edilmiştir. Tablo 2'de, Sülfonamitlerin literatürde bulunabilen $\mathrm{pK}_{\mathrm{a}}$ değerleri ve elde edilen $\mathrm{pK}_{\mathrm{a}}$ değerleri görülmektedir.
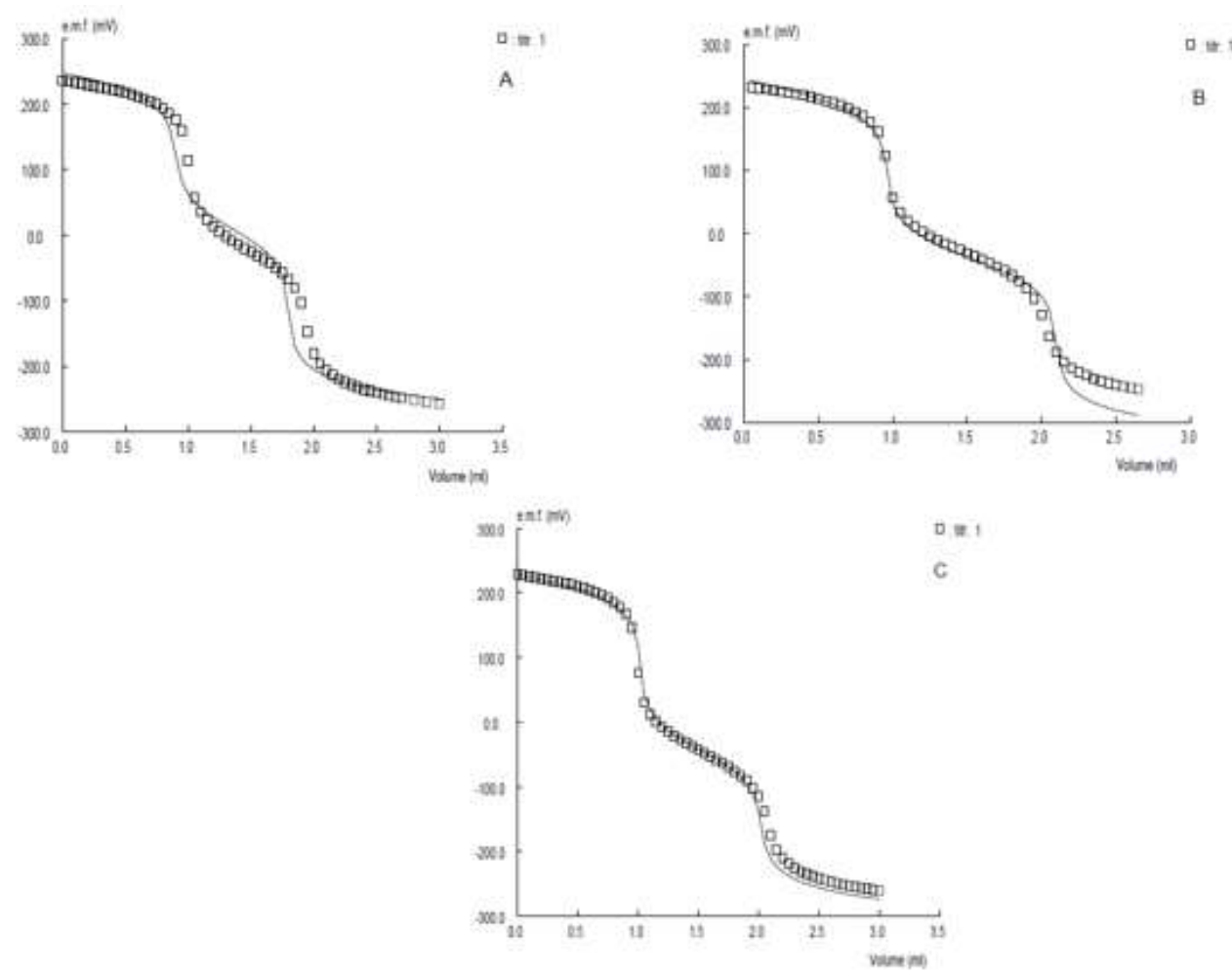

Şekil 3. Sülfodiazinin a) $\% 40$ Metanol ortamında b) $\% 50$ Metanol ortamında c) $\% 60$ Metanol ortamında PKPOT programıla elde edilmiş titrasyon grafiği 


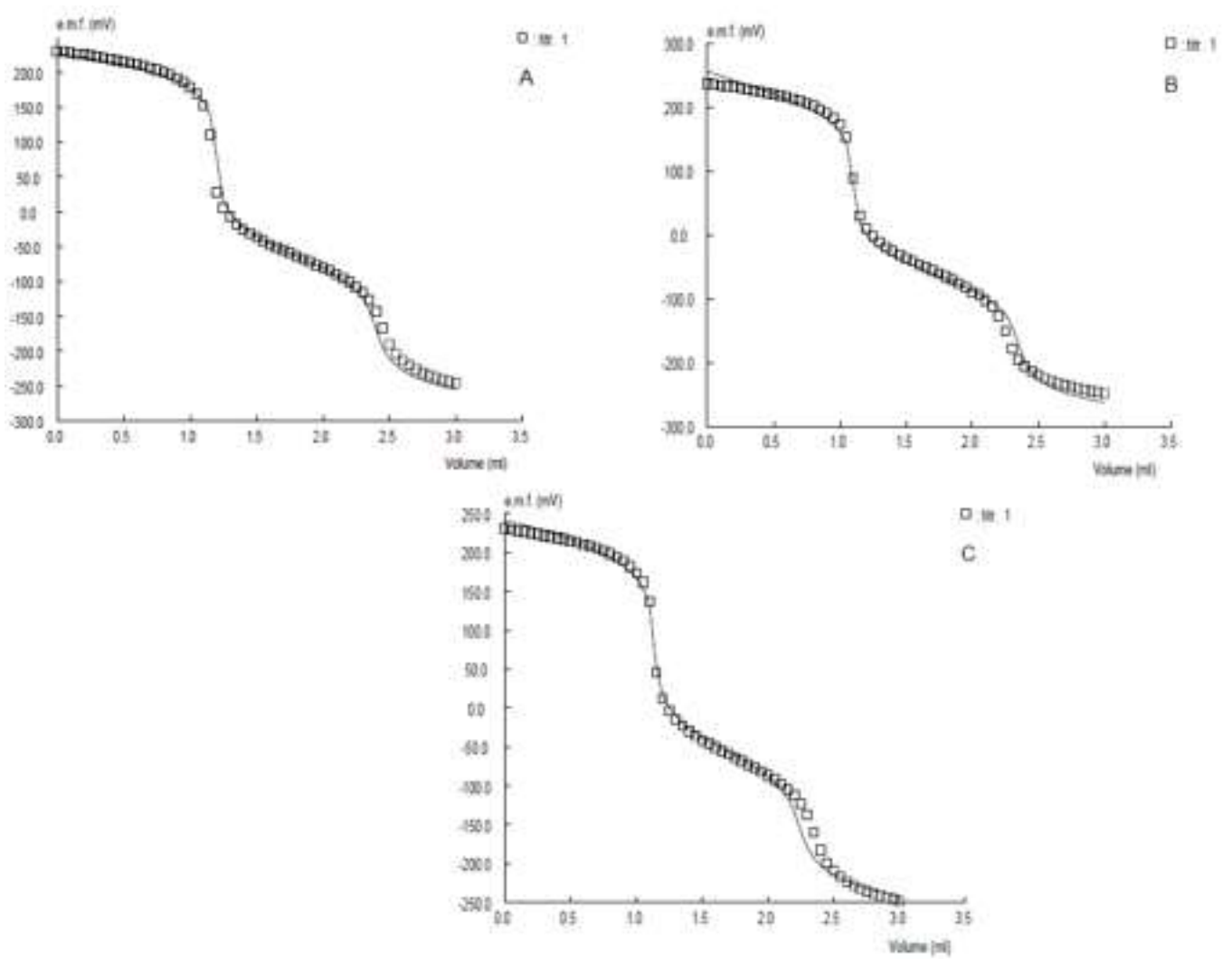

Şekil 4. Sülfomerazinin a) $\% 40$ Metanol ortamında b) \%50 Metanol ortamında c) $\% 60$ Metanol ortamında PKPOT programıyla elde edilmiş titrasyon grafiği
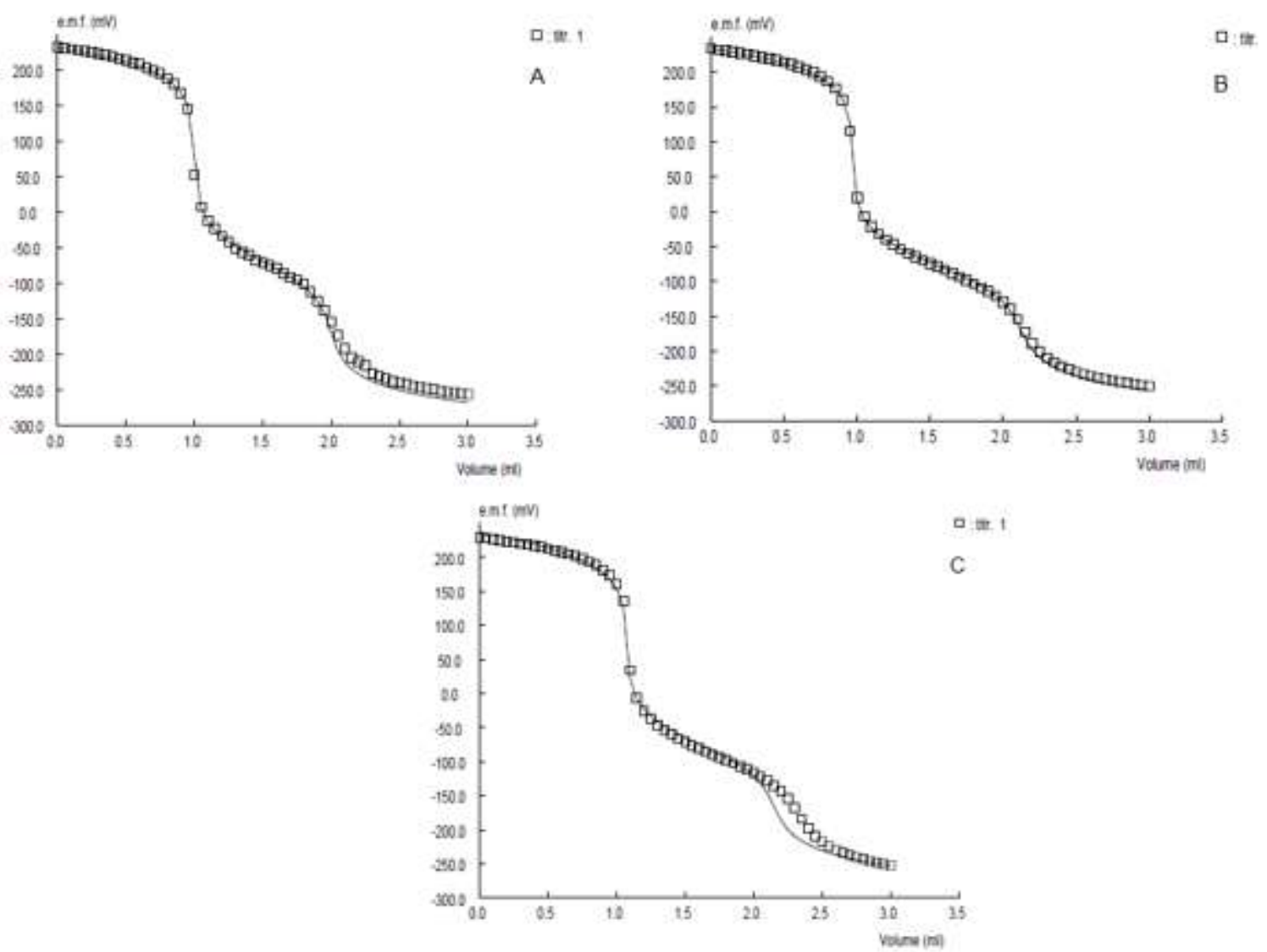

c

Şekil 5. Sülfometazinin a) $\% 40$ Metanol ortamında b) $\% 50$ Metanol ortamında c) $\% 60$ Metanol ortamında PKPOT programıyla elde edilmiş titrasyon grafiği 
Sülfonamitler yapısal olarak incelendiğinde $\mathrm{N}^{4}$ azot atomu ve $\mathrm{N}^{1}$ azot atomuna bağlı $\mathrm{R}$ grubu arasındaki mesafenin uzunluğuna rağmen, $\mathrm{R}$ sübstitüentinin sülfonamid türevlerinin $\mathrm{pK}_{\mathrm{a}}$ değerlerinde çok önemli bir rolü olduğu bilinmektedir [31]. Bu nedenle, $\mathrm{N}^{1}$ azot atomuna bağlı farklı $\mathrm{R}$ gruplarının $\mathrm{pK}_{\mathrm{a}}$ üzerindeki rolü dikkate alınmalıdır.

Çalışılan bileşikler için $\mathrm{N}^{4}$ azot atomu ile ilişkili $\mathrm{pK}_{\mathrm{a}}$ değerleri anilinin sudaki $\left(\mathrm{pK}_{\mathrm{a}}=4.60\right)$ [36, 37] türevleriyle gözlenen değerlerle kıyaslandığında para pozisyonunda elektron çeken bir sülfon grubuna bağlı olması sebebiyle daha küçük olduğu düşünülebilir. Sülfonamitlerde bulunan $\mathrm{N}^{1}$ grubu ile ilişkili $\mathrm{pK}_{\mathrm{a} 2}$ değerleri sülfonilamidin sudaki $\left(\mathrm{pK}_{\mathrm{a}}=10.1\right)[33,38]$ iyonlaşma sabitinden daha küçüktür. Bunun sebebi sülfonamid grubu bileşiklerde $\mathrm{N}^{1}$ üzerinde $\mathrm{H}$ yerine başka heterosiklik sübstitüent grupların varlığında rezonans ve indüktüf etki oluşması ile açıklanabilir [31].

Tablo 1. Çalışılan bileşiklerin \%40, 50 ve $60 \mathrm{v} / \mathrm{v}$ metanol-su ortamındaki potansiyometrik titrasyon yöntemiyle elde edilen $\mathrm{pK}_{\mathrm{a}}$ değerleri

\begin{tabular}{|c|c|c|c|c|c|c|c|}
\hline \multirow{3}{*}{ Bileşik } & \multirow{3}{*}{ Metot } & \multicolumn{6}{|c|}{ Metanol-su ortam yüzdeleri } \\
\hline & & \multicolumn{2}{|c|}{$(\% 40 \mathrm{v} / \mathrm{v})$} & \multicolumn{2}{|c|}{$(\% 50 \mathrm{v} / \mathrm{v})$} & \multicolumn{2}{|c|}{$(\% 60 \mathrm{v} / \mathrm{v})$} \\
\hline & & $\mathrm{pK}_{\mathrm{a} 1}$ & $\mathrm{pK}_{\mathrm{a} 2}$ & $\mathrm{pK}_{\mathrm{a} 1}$ & $\mathrm{pK}_{\mathrm{a} 2}$ & $\mathrm{pK}_{\mathrm{a} 1}$ & $\mathrm{pK}_{\mathrm{a} 2}$ \\
\hline & Gran & $\begin{array}{l}2.90 \\
\pm 0,056\end{array}$ & $\begin{array}{l}6.70 \\
\pm 0,000\end{array}$ & $\begin{array}{l}2.85 \\
\pm 0,038\end{array}$ & $\begin{array}{l}6.80 \\
\pm 0,173\end{array}$ & $\begin{array}{l}2.80 \\
\pm 0,046\end{array}$ & $\begin{array}{l}7.00 \\
\pm 0,000\end{array}$ \\
\hline Sülfodiazin & PKPOT & $\begin{array}{l}2.97 \\
\pm 0,059\end{array}$ & $\begin{array}{l}7.09 \\
\pm 0,025\end{array}$ & $\begin{array}{l}2.99 \\
\pm 0,119\end{array}$ & $\begin{array}{l}7.15 \\
\pm 0,055\end{array}$ & $\begin{array}{l}3.01 \\
\pm 0,031\end{array}$ & $\begin{array}{l}7.21 \\
\pm 0,021\end{array}$ \\
\hline & Gran & $\begin{array}{l}2.90 \\
\pm 0,017\end{array}$ & $\begin{array}{l}7.08 \\
\pm 0,029\end{array}$ & $\begin{array}{l}2.85 \\
\pm 0,000\end{array}$ & $\begin{array}{l}7.10 \\
\pm 0,000\end{array}$ & $\begin{array}{l}2.72 \\
\pm 0,000\end{array}$ & $\begin{array}{l}7.07 \\
\pm 0,029\end{array}$ \\
\hline & PKPOT & $\begin{array}{l}2.90 \\
\pm 0,105\end{array}$ & $\begin{array}{l}7.53 \\
\pm 0,074\end{array}$ & $\begin{array}{l}2.94 \\
\pm 0,097\end{array}$ & $\begin{array}{l}7.76 \\
\pm 0,101\end{array}$ & $\begin{array}{l}3.02 \\
\pm 0,020\end{array}$ & $\begin{array}{l}7.99 \\
\pm 0,006\end{array}$ \\
\hline Sülfomerazin & Gran & $\begin{array}{l}2.89 \\
\pm 0,000\end{array}$ & $\begin{array}{l}7.63 \\
\pm 0,098\end{array}$ & $\begin{array}{l}3.07 \\
\pm 0,040\end{array}$ & $\begin{array}{l}7.85 \\
\pm 0,000\end{array}$ & $\begin{array}{l}2.94 \\
\pm 0,012\end{array}$ & $\begin{array}{l}7.71 \\
\pm 0,000\end{array}$ \\
\hline Sülfometazin & PKPOT & $\begin{array}{l}2.81 \\
\pm 0,122\end{array}$ & $\begin{array}{l}7.70 \\
\pm 0,061\end{array}$ & $\begin{array}{l}3.00 \\
\pm 0,032\end{array}$ & $\begin{array}{l}8.02 \\
\pm 0,101\end{array}$ & $\begin{array}{l}3.21 \\
\pm 0,010\end{array}$ & $\begin{array}{l}8.34 \\
\pm 0,142\end{array}$ \\
\hline
\end{tabular}

Protonlanmış sülfodiazin yapısında $\mathrm{pK}_{\mathrm{a} 1}$ anilinyum protonuna, $\mathrm{pK}_{\mathrm{a} 2}$ ise pirimidin halkasındaki protona aittir. Protonlanmış sülfomerazin yapısında metil grubuna yakın veya uzak olan $\mathrm{N}$ üzerinden protonlanarak çift yüklü iyon halinde olduğu ve $\mathrm{pK}_{\mathrm{a} 1}$ anilinyum protonuna, $\mathrm{pK}_{\mathrm{a} 2}$ ise yapıya giren metil grubundan kaynaklı olarak sülfadiazinden daha zayıf davrandığı gözlenmiştir. Benzer şekilde sülfometazinin $\mathrm{pK}_{\mathrm{a} 2}$ değerindeki zayıflama da, yapıya giren ikinci metil grubundan kaynaklanmaktadır.

Çalışılan her bir ortamda farklı $\mathrm{pK}_{\mathrm{a}}$ değerlerinin elde edilmesi su- organik çözücü karışımlarının kullanıldığı durumlarda spesifik çözücü-çözünen etkileşimleri sonucu elektrostatik etkileşimlerin değişmesi olarak açıklanabilir. İkili karışımların olduğu bu ortamlarda, bu ikili karışımların yapısal özelliklerine ilişkin tercihli bir çözülme olayı mevcuttur. Metanol-su karışımlarında tercih edilen çözme, tercih edilen çözücü su olduğunda beklenenden daha düşük $\mathrm{K}_{\mathrm{a}}$ değerleri üretir. Ayrıca çözücünün çözme yeteneğinin ve dielektrik sabitinin ayrışma reaksiyonlarında önemli bir rol oynadığı gösterilmiştir [44]. sülfomerazinin, sülfodiazinin ve sülfometazinin $\mathrm{pK}_{\mathrm{a} 1}$ ve $\mathrm{pK}_{\mathrm{a} 2}$ değerleri metanol ortamında artmıştır. Bunun sebebi metanol ilavesiyle çözücünün dielektrik sabitinin azalmasıdır.

Su ortamında sülfonamitlere ait $\mathrm{pK}_{\mathrm{a}}$ değerleri ile ilgili çeşitli yayınlar olmasına rağmen, $[31,32$, 39-42] yapılan literatür taramasında metanol - su ikili karışımlarındaki $\mathrm{pK}_{\mathrm{a}}$ değerleri hakkında veriye rastlanmamıştır. $\mathrm{pK}_{\mathrm{a}}$ değerleri ile metanol-su karışımlarına ait solvatokromik parametreler arasında ilişkiler, bu bileşiklerin herhangi bir metanol-su ikili karışımındaki $\mathrm{pK}_{\mathrm{a}}$ değerlerinin hesaplanmasını mümkün kılmaktadır. Ayrıca bu çalışma ile elde edilen $\mathrm{pK}_{\mathrm{a}}$ değerleri bilgisi, analitik metodu geliştirmeye yardımcı olacak ve bu bileşiklerin asidik bazik davranışının daha iyi anlaşılmasını sağlayacaktır. 
Tablo 2. Sülfonamitlerin literatürde bulunabilen $\mathrm{pK}_{\mathrm{a}}$ değerleri ve Yasuda Shedlosky ekstrapolasyon yöntemiyle elde edilen $\mathrm{pK}_{\mathrm{a}}$ değerleri

\begin{tabular}{ccccc}
\hline Bileşik & \multicolumn{2}{c}{$\begin{array}{c}\text { diteratür } \\
\text { değerleri }\end{array}$} & \multicolumn{2}{c}{$\begin{array}{c}\text { Ekstrapolasyonla } \\
\text { bulunan değerler }\end{array}$} \\
\cline { 2 - 5 } Sülfodiazin & $\mathrm{pK}_{\mathrm{a} 1}$ & $\mathrm{pK}_{\mathrm{a} 2}$ & $\mathrm{pK}_{\mathrm{a} 1}$ & $\mathrm{pK}_{\mathrm{a} 2}$ \\
& 2.10 & $6.28^{32}$ & 2.915 & 6.936 \\
& - & $6.57^{31}$ & & \\
\hline \multirow{5}{*}{ Sülfomerazin } & $2.22 \pm 0.01$ & $6.80 \pm 0.01^{39}$ & 2.734 & 6.955 \\
& 2.17 & $6.77^{32}$ & & \\
& 2.17 & $6.77^{41}$ & & \\
& 2.3 & $7.0^{42}$ & & \\
Sülfomehazin & - & $7.14^{31}$ & & \\
& $2.37 \pm 0.01$ & $7.49 \pm 0.01^{39}$ & 2.304 & 6.902 \\
& 2.28 & $7.42^{32}$ & & \\
& 2.28 & $7.49 \pm 0.13^{40}$ & & \\
& 2.4 & $7.42^{41}$ & & \\
& - & $7.4^{42}$ & & \\
& - & $7.31^{31}$ & & \\
\hline
\end{tabular}

\section{Sonuç ve Öneriler}

Potansiyometri yöntemi, iyonlaşma sabitlerinin tayininde su-organik çözücü karışımlarında çalışıldığında hem kullanımındaki kolaylıklar nedeniyle hem de yeterli doğruluk ve kesinlik sağlaması sebebiyle tercih edilen bir yöntemdir. Bu çalışmada çalışılan sülfonamitlerin (sülfodiazin, sülfomerazin ve sülfometazinin) $\mathrm{pK}_{\mathrm{a} 1}$ ve $\mathrm{pK}_{\mathrm{a} 2}$ değerlerinin tespiti ile bu ilaçların absorpsiyon özellikleri ve bileşiklerin hedef yapısındaki yapısal gruplar daha iyi aydınlatılmıştır. Sülfonamitler genel olarak yapılarındaki R grubunun etkisinde $\mathrm{pK}_{\mathrm{a}}$ değerleri değişmektedir. Ayrıca sonuçlar, sülfonamitlerin $\mathrm{pK}_{\mathrm{a}}$ değerlerinin, çözeltilere eklenen organik çözücü yüzdelerinden etkilendiğini göstermektedir. Bu ilaçların $\mathrm{pK}_{\mathrm{a}}$ değerlerinin bilinmesiyle ilaç formülasyonlarında yapısal özellik, ilaç etken maddesi tasarımı, biyolojik aktiflik konularının yanısıra ilaçların analizlerinde metot geliştirme alanında çalışan araştırmacılara önemli bir kaynak olacaktır.

\section{Teșekkür}

Bu çalışma Yüksek Lisans Tez Projesi olarak, Bilimsel Araştırma Projeleri Yönetim Birimi tarafından YL-1060 numaralı proje olarak desteklenmiştir. Süleyman Demirel Üniversitesi Araştırma Projeleri Yönetim birimine teşekkür ederim.

\section{Yazarların Katkısı}

Dilara BAŞAT DERELİ, bu çalışmada deneyleri yaparak veri değerlendirmesinde katkı sağlamıştır. Abbase Güleren ALSANCAK, Yüksek Lisans Tez danışmanlığı yaparak projeyi planlamış ve verilerin değerlendirilmesinde katkı sağlamıştır.

\section{Çıkar Çatışması Beyanı}

Yazarlar arasında herhangi bir çıkar çatışması bulunmamaktadır.

\section{Araştırma ve Yayın Etiği Beyanı}

Yapılan çalışmada araştırma ve yayın etiğine uyulmuştur. 


\section{Kaynaklar}

[1] Kishore D., Pareek A. 2013. A short review on sulphonamides. International journal of pharma and bio sciences, 4: 812-820.

[2] Gomes J.R.B., Gomes P. 2005. Gas-phase acidity of sulfonamides: implications for reactivity and prodrug design. Tetrahedron, 61: 2705-2712.

[3] Özalp E.A.D. 2002. Farmakoloji. Nobel T1p Kitabevleri, İstanbul, 1-804.

[4] Yousef F., Mansour O., Herbali J. 2018. Sulfonamides: Historical Discovery Development (Structure-Activity Relationship Notes). In-vitro In-vivo In-silico Journal, 1 (1): 1-15.

[5] Dragostin O.M.P, Lapuşcu F.G, Pânzariu A, Vasincu I.G, Profire L. 2013. Importance of Sulfonamide Moiety in Current and Future Theraphy. Revista medico-chirurgicala a Societatii de Medici si Naturalisti din Iasi, 117 (2): 558-564.

[6] Demiralay E.Ç., Basat D., Canbay H.S., Alsancak G., Uslu B. 2012. Determination of $\mathrm{pK}_{\mathrm{a}}$ values of opipramol in acetonitrile-water binary mixtures by using chromatographic and spectrophotometric Methods. Global Journal of Analytical Chemistry, 3 (11): 1-9.

[7] Rossotti J.C., Rossotti H. 1961. The Determination of Stability Constants. McGraw-Hill, New York, 1-425.

[8] Paul W.W., Lois E.W. 1966. Spectrophotometric determination of the acid dissociation constants of 3-hydroxypyridine. Analytical Biochemistry, 15 (3): 421-425.

[9] Demiralay E.Ç., Yılmaz H. 2012. Potentiometric $\mathrm{pK}_{\mathrm{a}}$ Determination of Piroxicam and Tenoxicam in Acetonitrile-Water Binary Mixtures. SDU Journal of Science, 7 (1): 34-44.

[10] Benet L.Z., Goyan J.E. 1967. Potentiometric determination of dissociation constants. Journal of Pharmaceutical Sciences, 56 (6): 665-680.

[11] Sixma F.L.J., Wynberg H. 1964. A Manual of Physical Methods in Organic Chemistry. John Wiley \& Sons, Inc., New York, 1-342.

[12] Kroflic A., Apelblat A., Bešter-Rogac M. 2012. Dissociation constants of parabens and limiting conductances of their ions in water. The Journal of Physical Chemistry B, 116 (4): 1385-1392.

[13] Rabenstein D.L., Sayer T.L. 1976. Determination of microscopic acid dissociation constants by nuclear magnetic resonance spectrometry. Analytical Chemistry, 48 (8): 1141-1146.

[14] Zimmerman I. 1982. Determination of $\mathrm{pK}_{\mathrm{a}}$ values from solubility data. International Journal of Pharmaceutics, 13 (1): 57-65.

[15] Horvath C., Melander W., Molnár I. 1977. Liquid chromatography of ionogenic substances with nonpolar stationary phases (Solvophobic Theory of Reversed Phase Chromatography, Part II). Analytical Chemistry, 49 (1): 142-154.

[16] Demiralay E.Ç., Alsancak G., Ozkan S.A. 2009. Determination of $\mathrm{pK}_{\mathrm{a}}$ values of nonsteroidal antiinflammatory drug-oxicams by RP-HPLC and their analysis in pharmaceutical dosage forms. Journal of Separation Science, 32 (17): 2928-2936.

[17] Beltran J.L., Sanli N., Fonrodona G., Barron D., Özkan A.G., Barbosa J. 2003. Spectrophotometric potentiometric and chromatographic $\mathrm{pK}_{\mathrm{a}}$ values of polyphenolic substances in water and acetonitrile water media. Analytica Chimica Acta, 484 (2): 253-264.

[18] Chung T.D., Kim H. 2001. Voltammetric determination of the $\mathrm{pK}_{\mathrm{a}}$ of various acids in polar aprotic solvents using 1,4-benzoquinone. Journal of Electroanalytical Chemistry, 498 (1-2): 209215.

[19] Tajc S.G., Tolbert B.S., Basavappa R., Mille B.L. 2004. Direct determination of thiol $\mathrm{pK}_{\mathrm{a}}$ by isothermal titration microcalorimetry. Journal of the American Chemical Society, 126 (34): 10508-10509.

[20] Fuguet E., Ràfols C., Bosch E., Roses M. 2009. Fast highthroughput method for the determination of acidity constants by capillary electrophoresis. Journal of Chromatography A, 1216 (17): 36463651.

[21] Rosenberg L.S., Simons J., Schulman S.G. 1979. Determination of $\mathrm{pK}_{\mathrm{a}}$ values of N-heterocyclic bases by fluorescence spectrophotometry. Talanta, 26 (9): 867-871.

[22] Katzin L.I., Gulyas E. 1960. Dissociation constants of tartaric acid with the aid of polarimetry. Journal of Physical Chemistry, 64 (11): 1739-1741.

[23] Bunnett J.F., Nudelman N.S. 1969. Independent, Kinetic Method for Determining Acid Dissociation Constants in Methanol. Journal of Organic Chemistry, 34 (7): 2043-2046. 
[24] Tehan B.G., Lloyd E.J., Wong M.G., Pitt W.R., Montana J.G. 2002. Estimation of $\mathrm{pK}_{\mathrm{a}}$ using semi empirical molecular orbital methods. Part 1: Application to phenols and carboxylic acids, QSAR, 21 (5): 457-472.

[25] Gran G. 1952. Determination of the equvalence points in potentiometric titrations. Part II, Analyst, 77: 661-671.

[26] Gran G. 1988. Equivalence volumes in potentiometric titrations. Analytica Chimica Acta, 206: 111-123.

[27] Levie R. 1997. Principles of quantitative chemical analysis. McGraw-Hill College Press, Singapore, 1-737.

[28] Yasuda M. 1959. Dissociation constants of some carboxylic acids in mixed aqueous solvents. Bulletin of the Chemical Society of Japan, 32: 429-432.

[29] Shedlovsky T. 1962. Electrolytes. Edited by Pesce B., Pergamon Press, NewYork, 1-455.

[30] Barbosa J., Barrón D., Beltrán J.L., Nebot V.S. 1995. PKPOT, a program for the potentiometric study of ionic equilibria in aqueous and non-aqueous media. Analytica Chimica Acta, 317: 7581.

[31] Sanli N., Sanli S., Özkan G., Denizli A. 2010. Determination of $\mathrm{pK}_{\mathrm{a}}$ Values of Some Sulfonamides by LC and LC-PDA Methods in Acetonitrile-Water Binary Mixtures. The Journal of the Brazilian Chemical Society, 21 (10): 1952-1960.

[32] Lin C.E., Chang C.C., Lin W.C.J. 1997. Migration behavior and separation of sulfonamides in capillary zone electrophoresis III. Citrate buffer as a background electrolyte. Journal of Chromatography A, 768: 105-112.

[33] Babić S., Horvat A.J.M., Pavlović D.M., Macan M.K. 2007. Determination of $\mathrm{pK}_{\mathrm{a}}$ values of active pharmaceutical ingredients. Trends in Analytical Chemistry, 26 (11): 1043-1061.

[34] Benet L.Z., Goyan J.E. 1967. Potentiometric determination of dissociation constants. Journal of Pharmaceutical Sciences, 56: 665-680.

[35] Albert A., Serjeant E.P. 1984. The Determination of Ionization Constants. Chapman and Hall Press, London, 1-216.

[36] Altun Y. 2004. Study of Solvent Composition Effects on the Protonation Equilibria of Various Anilines by Multiple Linear Regression and Factor Analysis Applied to the Correlation Between Protonation Constants and Solvatochromic Parameters in Ethanol-Water Mixed Solvents. Journal of Solution Chemistry, 33 (5): 479-497.

[37] Polster J., Lachmann H. 1989. Spectrometric Titrations: Analysis of Chemical Equilibria. VCH Weinheim Press, NewYork, 1-433.

[38] Maren T.H., Conroy C.W. 1993. A New Class of Carbonic Anhydrase Inhibito. The Journal of Biological Chemist., 268 (35): 26233-26239.

[39] Völgyi G., Ruiz R., Box K, Comer J., Bosch E., Takács-Novák K. 2007. Potentiometric and spectrophotometric $\mathrm{pK}_{\mathrm{a}}$ determination of water-insoluble compounds: validation study in a new cosolvent system. Anal. Chim. Acta, 583 (2): 418-428.

[40] Qiang Z., Adams C. 2004. Potentiometric determination of acid dissociation constants ( $\mathrm{pK}_{\mathrm{a}}$ ) for human and veterinary antibiotics. Water Res., 38 (12): 2874-2890.

[41] Lin C.E., Chang C.C., Lin W.C. 1997. Migration behavior and separation of sulfonamides in capillary zone electrophoresis II. Positively charged species at low Ph. Journal of Chromatography A, 759 (1-2): 203-209.

[42] Ricci M.C., Cross R.F. 1993. Capillary electrophoresis seperation of sulphonamides and dihydrofolate reductase inhibitors. J. Microcol. Sep., 5: 207-215.

[43] Maren T.H., Conroy C.W.J. 1993. A new class of carbonic anhydrase inhibitor. Biol. Chem., 268, 26233.

[44] Guttmann V. 1960. Coordination Chemistry in Nonaqueous Solutions. Springer Press, New York, $1-174$. 